\title{
Screening of Donated Blood for Transfusion Transmitted Infections by Serology and Response Rate to Notification of Reactive Results: A Tertiary Care Institutional Experience
}

\author{
Rohit Vasantbhai Bhalara, Payal Shah, Ravi Kirit kumar Kothari* and Gauravi Dhruva \\ Department of Pathology, Pandit Dindayal Upadhyay Medical College, Rajkot
}

\begin{abstract}
Background: Safety for blood Transfusion begins with healthy donors. A basic part of preventing transfusion transmitted infections (TTIs) is to notify and counsel reactive donors. This study analysed trends in the prevalence of transfusion-transmissible infectious pathogens among blood donors and notify them as well as to assess response rate among them. Donor notification and counselling protect the health of the donor and stop secondary transmission of infectious diseases.

Methods: 38707 blood donations were screened for TTIs, namely, HIV, HBV, HCV, and syphilis, Malarial Parasite by serology. ELISA testing for anti-HIV antibody, anti-HCV antibody and HBsAg and RPR test for syphilis, Rapid card test for Malarial Parasite. All reactive donors were retested in duplicate and notified of their status by communicating through telephone.

Result: We evaluated $341(0.88 \%)$ cases with reactive screening test results $(0.617 \% \mathrm{HBV}, 0.016 \% \mathrm{HCV}, 0.134 \% \mathrm{HIV}$, $0.08 \%$ syphilis, $0.031 \%$ Malaria ). Only 179 donors $(52.5 \%)$ responded to notification. The response among voluntary donors was better as compared to the replacement donors $(54.1 \%$ versus $40.7 \%)$. Only $101(57.22 \%)$ responsive donors followed their first attendance at referral clinic.

Conclusion: Our study provides prevalence rate of TTIs among blood donors and importance of proper donor counselling and notification of TTI status to all reactive donors who opt to receive this information.
\end{abstract}

Keywords: Blood Donor Counselling, TTInotification, ELISA

\section{Introduction}

Although blood transfusion can be a life saving type of therapy for medical and surgical patients, unsafe transfusion practices can put millions of people at risk of transfusion transmitted infections (TTIs). ${ }^{[1-3]}$ The safety of the blood supply can be ensured by monitoring the prevalence of TTI markers in the donor population. Blood transfusion is safer than ever before through continuous improvements in donor recruitment, screening, testing of donated blood with increasingly sensitive assays, and appropriate clinical use of blood. ${ }^{[4]}$ Serologic testing for transfusion transmitted diseases has historically been the foundation of blood screening. ${ }^{[5]}$ Moreover, threat of infectious agents entering the blood circulation isn't static and may evolve as new pathogens emerge or as old ones change their epidemiological pattern. ${ }^{[6]}$ After blood donation, samples are collected for screening for anti-HIV-1/2, anti-HCV, and HBsAg, RPR for syphilis, and slide/card test for malaria.

In 2002, the Govt of India adopted the National Blood Policy "An action plan for blood safety" to make sure safe blood supply. This policy advocates notification to all or any reactive blood donors. Blood banks are thus now required to get written consent from donors at time of donation for screening blood for TTI (Transfusion- transmitted Infections) and whether or not they wish to be informed about their abnormal tests results. ${ }^{[7]}$ Most blood banks discard blood that's TTI reactive but do not notify donors of their TTI status thanks to a scarcity of resources and trained counsellors. ${ }^{(8)}$

In our study If any of the screening tests are abnormal, before notification to the donors the tests are repeated using two assays of differing principles and in duplicate with an equivalent assay so as to avoid notification of falsepositive results.

Blood donors with reactive screening test results are informed by phone call and are requested to come for counselling and are referred to integrated counselling and testing center (ICTC) for HIV and STD clinic for $\mathrm{HBV} / \mathrm{HCV}$ and syphilis, respectively, for counseling, confirmatory testing, and management. Although the blood policy advocates disclosure of TTI status, donors aren't in practice, informed about their results. The onus lies with the donor to contact the blood bank. So counselling, testing, and notification together form the vital link between the donor and safe blood. ${ }^{[8]}$

As most of the donors don't expect to listen that they have reactive results, they'll become extremely distressed to 
know this news. These donors may be highly motivated to donate, having desire to assist others, or just want a while off work or may have other motives. This, unfortunately, may leave the donor with a negative feeling towards blood donation or diminish his/her self-worth ${ }^{[9,10]}$. On the other hand, a small minority of people appear to ignore notification and still donate blood elsewhere.

Donor notification can therefore be a challenging task demanding special skills from the staff involved who should be prepared to meet new challenges and help donor come to terms with their newly discovered status. We undertook this study to assess the prevalence of TTIs using serology and determine the response rate following notification of reactive status to the donors.

\section{Materials and Methods}

The present study was an observational study in the form of data analysis performed in Blood Bank of Department of Pathology at P D U Government Hospital in Rajkot from January 2017 to December 2018 total 2 year period. The blood bank at our hospital provides blood for the patients after mandatory TTI testing which was done with the fourth generation ELISA for anti HIV 1/2 and third generation ELISA for $\mathrm{HBsAg}$ and $\mathrm{HCV}$ and rapid card test for malarial parasite on blood donor's samples. The tests for syphilis were rapid plasma regain (RPR) with flocculation principle.

If initial serology result was positive, sample was retested again in duplicate. Whenever the results of serology were found to be positive, blood unit was discarded as per hospital SOPs and donor was notified of his/her status either by telephone through counsellor and give advice to report to the blood bank and for referral to the respective department of the hospital for further management.

In this study, we evaluated the response rate of TTIs reactive donors after notification of their abnormal test results. The case was closed only if the donor did not respond to any of the three telephone calls. In case of HIV before labeling as nonresponder, the donor's details were shared with DAPCU (District Aids Prevention And Control Unit) for contact to be done by the network of peripheral social workers.

\section{Result}

Total 38707 blood donors had donated during the study period. Out of total donations, 38637 (99.81\%) donors were voluntary and $341(0.88 \%)$ blood donors were found to be TTI markers reactive. The gender-wise distribution was as follows: there were 36784 males and 1923 female donors. As per the age-wise distribution, 12153 donors were in 18-24 years age group, 21888 were in $25-40$ years age group, 4666 in 41-55 years age group.

A total of 38707 donors were evaluated comprising $0.18 \%$ replacement and $99.81 \%$ voluntary donors. The majority of the donors $(97.06 \%)$ donated blood for the first time. The demographic details of donors are given in Table 1.

The HIV reactive responders were referred to the ICTC for counselling and confirmatory testing while the HBV, $\mathrm{HCV}$, Syphilis and malaria were referred to a physician for further management.

Out of these 341 reactive donors, 179 (52.5\%) includes both voluntary and replacement donors responded positively to the notification calls and attended counselling at the blood bank and attached government hospital. Among $162(47.5 \%)$ reactive donors who did not respond to the notification, the major reasons were donor's busy schedule, donor's residing out of station and unwilling to visit the blood bank again. The response among voluntary donors was better as compared to the replacement donors. (54.1\% versus $40.7 \%$ ) these details mentioned in table 4 and Figure 2. Only $101(55.80 \%)$ responsive donors followed their first attendance at referral specialties.

Table 1: Demographic details of blood donations ( $n=38707$ donors).

\begin{tabular}{|l|l|l|}
\hline Gender & Number & Percentage \\
\hline Male & 36784 & 95.04 \\
\hline Female & 1923 & 4.96 \\
\hline Donation type & & \\
\hline Voluntary & 38637 & 99.81 \\
\hline Replacement & 70 & 0.18 \\
\hline Donor repeatability & & \\
\hline First time donors & 37570 & 97.06 \\
\hline Repeat donor & 1137 & 2.93 \\
\hline Age group & & \\
\hline
\end{tabular}




\begin{tabular}{|l|l|l|}
\hline Gender & Number & Percentage \\
\hline $18-24$ & 12153 & 31.40 \\
\hline $25-40$ & 21888 & 56.54 \\
\hline $41-55$ & 4666 & 12.06 \\
\hline
\end{tabular}

Table 2: Year wise, gender wise and type of donation (voluntary or replacement) distribution of total blood donations.

\begin{tabular}{|l|l|l|l|l|}
\hline Year & Male & Female & Replacement & Voluntary \\
\hline 2017 & 16958 & 716 & 43 & 17631 \\
\hline 2018 & 19826 & 1207 & 27 & 21006 \\
\hline Total & $\mathbf{3 6 7 8 4}$ & 1923 & $\mathbf{7 0}$ & 38637 \\
\hline
\end{tabular}

Table 3: Prevalence of TTI was $\mathbf{0 . 6 1 7} \%$ for HBV, $\mathbf{0 . 0 1 6} \%$ for HCV, $\mathbf{0 . 1 3 4 \%}$ for HIV, $\mathbf{0 . 0 8 \%}$ for Syphilis, $0.031 \%$ for Malaria.

\begin{tabular}{|l|l|l|l|}
\hline Total donor screened & Total reactive donor & Reactivity for test & \% Prevalence of TTls \\
\hline 38707 & 52 & HIV & 0.134 \\
\hline 38707 & 239 & HBV & 0.617 \\
\hline 38707 & 06 & HCV & 0.016 \\
\hline 38707 & 32 & Syphilis & 0.08 \\
\hline 38707 & 12 & Malarial Parasite & 0.031 \\
\hline
\end{tabular}

Table 4: Response among voluntary donors was better as compared to the replacement donors. (54.1\% versus $40.7 \%)$.

\begin{tabular}{|c|c|c|c|c|c|c|c|}
\hline \multirow{2}{*}{$\begin{array}{l}\text { Name of } \\
\text { serology } \\
\text { tests }\end{array}$} & \multirow[t]{2}{*}{$\begin{array}{l}\text { Reactive } \\
\text { donors }\end{array}$} & \multicolumn{3}{|c|}{$\begin{array}{l}\text { Voluntary } \\
\text { Donors }\end{array}$} & \multicolumn{3}{|c|}{$\begin{array}{l}\text { Replacement } \\
\text { Donors }\end{array}$} \\
\hline & & Notified & Responded & $\%$ & Notified & Responded & $\%$ \\
\hline HBV & 239 & 223 & 117 & 52.4 & 16 & 05 & 31.2 \\
\hline $\mathrm{HCV}$ & 06 & 04 & 02 & 50 & 02 & 01 & 50 \\
\hline HIV & 52 & 47 & 27 & 57.44 & 05 & 03 & 60 \\
\hline Syphilis & 32 & 30 & 17 & 56.6 & 02 & 01 & 50 \\
\hline Malaria & 12 & 10 & 7 & 70 & 02 & 01 & 50 \\
\hline Total & 341 & 314 & 170 & 54.1 & 27 & 11 & 40.7 \\
\hline
\end{tabular}

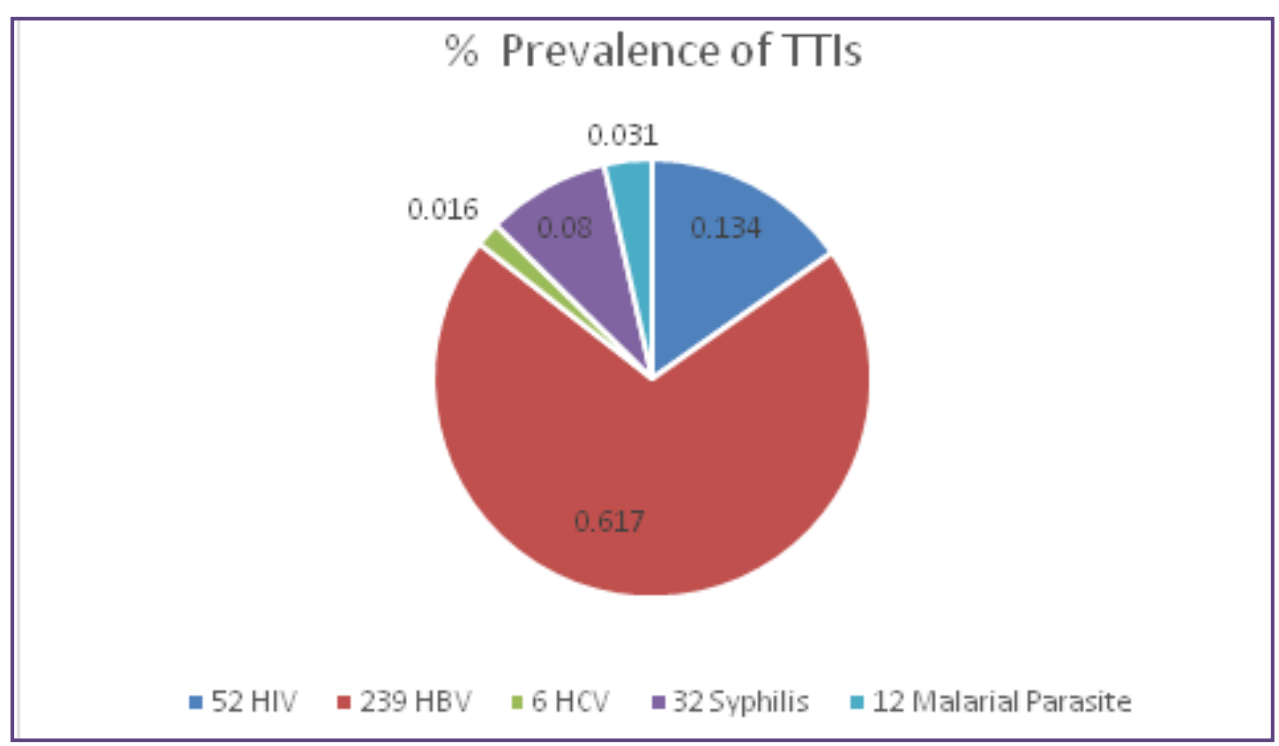

Fig. 1: Prevalence of TTI was $0.617 \%$ for $\mathrm{HBV}, \mathbf{0 . 0 1 6} \%$ for $\mathrm{HCV}, \mathbf{0 . 1 3 4 \%}$ for HIV, $\mathbf{0 . 0 8 \%}$ for Syphilis, $0.031 \%$ for Malaria. 


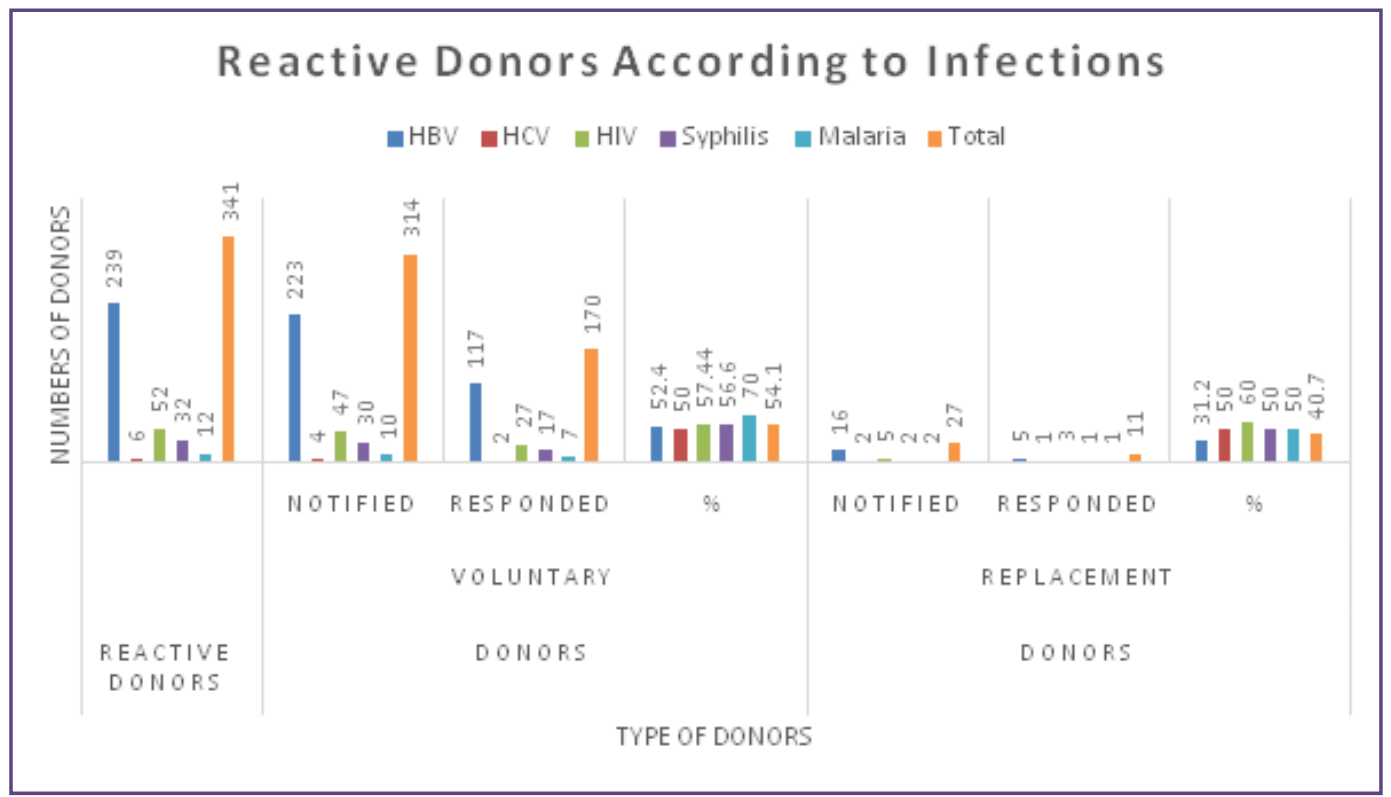

Fig. 2: response among voluntary donors was better as compared to the replacement donors. (54.1\% versus $40.7 \%)$.

\section{Discussion}

With over 93 million Blood donations made per annum worldwide, transfusion continues to save lots of many lives annually and improve the anticipation and quality of life of patients suffering from life-threatening conditions. ${ }^{[11]}$ At an equivalent time, transfusion is a crucial mode of transmission of infection to the recipients. Prevalence of TTI in India is $1.8-4 \%, 0.4-$ $1.09 \%, 0.2-1 \%$, and $0.05-0.9 \%$ for $\mathrm{HBV}, \mathrm{HCV}, \mathrm{HIV}$, and syphilis, respectively. ${ }^{[12-17]}$ Prevalence of TTI in the present study was in agreement with other seroprevalence studies carried out in various parts of India.

Transfusion safety begins with healthy donors. A fundamental a part of preventing TTI is to notify and counsel reactive donors. Donor notification and counselling protect the health of the donor, prevent secondary transmission of infectious diseases to sexual partners, reduces risk of vertical transmission and supply feedback about the effectiveness of donor selection procedures such as pre-donation education and medical history. ${ }^{[18]}$

We attempted to contact 341 reactive donors about their TTI status telephonically. Only 181 (53.1\%) reactive donors responded to the notification. In an Indian study by Patel et al. $236(60.36 \%)$ donors showed a positive response following donor notification ${ }^{[7]}$ In another study by Agarwal et al. involving 416 reactive donors, only $249(59.8 \%)$ donors turned to transfusion facility and attended counselling after receipt of their reactive status [19] The counselling success rate at large blood centre in southern India was $41.18 \%, 11.11 \%$, and $14.63 \%$ for $\mathrm{HBV}, \mathrm{HIV}$, and HCV, respectively. ${ }^{[20]}$

Donor response rate in our study was nearly equal as compared to other studies from the country. In our study non responders are $160(46.9 \%)$. This may flow from to poor health care knowledge, social stigma related to TTIs (especially HIV), and inadequate understanding of implications of screening tests among the overall population. ${ }^{[20,21]}$ Also, as many of the donors' belonged to far-off places; thus distance could be a reason for the donors not reporting back to transfusion facility. It is difficult to ensure that every donor had understood the meaning and intent of counselling to the best of his/her intelligence. The study by Kleinman et al. reports that following notification $27 \%$ of donors contacted the blood centre for further information. ${ }^{[22]}$

One more finding of this study that should be a serious concern for blood transfusion authorities is that only $101(55.8 \%)$ of 181 responsive donors responded to the first call and followed up their attendance at the ICTC or with the physicians they were asked to satisfy . This raises questions about the way donors are counselled and made aware of the consequences of not taking proper treatment.

As per objective 4.16 of the Indian action plan for blood safety, the blood donors are counselled about TTIs prior to donation and are offered the option of knowing their seroreactive status provided they give their consent. Low donor response rate suggest that we aren't ready to meet this goal with reasonable satisfaction. 
Transfusion safety rests heavily on the health of blood donors. To improve donor response rate, we've switched to exclusive telephonic notification to all or any donors who test reactive in screening tests. Donors should undergo optimal pre-donation counselling so as to educate them about the risk of infections and the window period. It is the collective duty of transfusion community to tell these donors and do the maximum amount as possible to allay their anxiety about reactive result and to advise them about available treatment.

\section{Conclusion}

Our study was a small endeavour in determining reactive blood donors' prevalence and their response rate when informed about their reactive status according to results based on screening assay for HIV, HBV, HCV by ELISA, Syphilis by RPR and Malarial Parasite by Rapid Card. To achieve 100\% response rate for contacted reactive donors, it's required to teach the donors at the time of donation about the varied TTI, window period, screening tests done, and therefore the importance of informing them the test results. It is also of equal weightage to make donor understand that correct and complete demographic data are crucial for blood bank for informing them test results besides calling them in case of non-availability of blood inventory. There is an urgent got to formulate the nationally acceptable guidelines for notification of all reactive donors.

\section{Acknowledgements}

I Heartily thank Dr. Gauravi A Dhruva, Professor and head, Department of Pathology, Pandit Dindayal Upadhyay Medical College, Rajkot For her help, valuable advice and suggestions.

\section{Reference}

1. Leena M S,Mohd S. Trend and prevalence of transfusion transmitted infections among blood donors in rural teaching institute, South India. J Pathol Nepal.2012;2:203-206.

2. Fessehaye F, Naik D, Fessehaye T.Transfusion transmitted infections - a retrospective analysis from the National Blood Transfusion Service in Eritrea.Pan Afr Med J.2011;9:40.

3. Buseri F I,Muhibi M A, Jeremiah Z A. Seroepidemiology of transfusion transmissible infectious diseases among blood donors in Osogbo, south west Nigeria.Blood Transfus. 2009;7:293-299.

4. Z. S. Bharucha, "Safe blood transfusion practices," Indian Journal of Pediatrics, vol.68,no.2,pp.127-131,2001.

5. R. Hans and N. Marwaha, "Nucleic acid testing-benefits and constraints," Asian Journal of Transfusion Science, vol. 8, no. 1, pp.2-3,2014.
6. F. Bihl, D. Castelli, F. Marincola, R. Y. Dodd, and C. Brander, "Transfusion-transmitted infections," Journal of Translational Medicine,vol.5, article25,2007.

7. D.P.Patel, D.S.Patel, D.J.Bhatt, D.N.Bhatnagar,and D.M.G. Shah, "Evaluation of response to donor notification of reactive transfusion transmitted infections(ttis) result,"National Journal of Integrated Research in Medicine,vol.3,no.2,pp.20-25,2012

8. Choudhury L P, Tetali S. Ethical challenges in voluntary blood donation in Kerala, India. J Med Ethics 2007;33: 1402.

9. L.A.Bashawri,"Are view of predonation blood donor deferrals in a university hospital," Journal of Family and Community Medicine,vol.12,no.2,pp.79-84,2005.

10. K. A. Munsterman, A. J. Grindon, M. T. Sullivan et al., "Assessment of motivations for return donation among deferred blood donors,"Transfusion,vol. 38, no.1,pp.45-50,1998.

11. Global blood safety and availability. Key facts and figures, 2010.

12. P.KaurandS.Basu, "Transfusion transmitted infections: existing and emerging pathogens,"Journal of Postgraduate Medicine, vol.51,no.2,pp.146-151,2005.

13. D.Arora,B.Arora, and A.Khetarpal,"Seroprevalence of HIV, HBV,HCV and syphilis in blood donors in Southern Haryana," Indian Journal of Pathology and Microbiology,vol.53,no.2,pp. 308-309,2010.

14. P. Pallavi, C. K. Ganesh, K. Jayashree, and G. V. Manjunath, "Seroprevalence and trends in transfusion transmitted infections among blood donors in a University Hospital blood bank: a 5 year study," Indian Journal of Hematology and Blood Transfusion,vol.27,no.1,pp.1-6,2011.

15. K. Chatterjee, P. Coshic, M. Borgohain, R. M. Thapliyal, S. Chakroborty, and S. Sunder, "Individual donor nucleic acid testing for blood safety against HIV-1 and hepatitis b and c viruses in a tertiary care hospital,"National Medical Journal of India,vol.25,no.4,pp.207-209,2012.

16. T.Chandra, S.N.F.Rizvi, and D.Agarwal,"Decreasing prevalence of transfusion transmitted infection in Indian scenario," The Scientific World Journal, vol. 2014, Article ID 173939, 4 pages, 2014.

17. M. Meena, T. Jindal, and A. Hazarika, "Prevalence of hepatitis B virus and hepatitis virus among blood donors at tertiary care hospital in India: a five-year study,"Transfusion, vol.51, no. 1,pp. 198-202,2011.

18. C. Bianco and D. Kessler, "Donor notification and counselling management of blood donors with positive test results," Vox Sanguinis,vol.67,no.3,pp.255-259,1994

19. N.Agarwal,"Response rate of blood donors in the uttarakhand region of india after notification of reactive test results on their blood samples," Blood Transfusion, vol. 12, no. 1, pp. s51-s53, 2014. 
20. S. Dontula, A. Mathur, T. Kamaladoss, S. Adimurthy, and L. Jagannathan, "Donor disclosure - a donor's right and blood bank's responsibility," Transfusion Alternatives in Transfusion Medicine, vol. 12, no.3-4,pp. 44-50,2012.

21. N. Choudhury, P. Singh, and H. Chandra, "AIDS awareness in blood donors in northIndia,'Transfusion Medicine,vol. 5, no. 4,pp.267-271,1995.

22. S. Kleinman, B. Wang, Y. Wu et al., "The donor notification process from the donor's perspective,'Transfusion, vol.44,no. 5,pp.658-666,2004.

*Corresponding author:

Ravi Kirit kumar Kothari, "Satyam”, 2- Ramnagar, Gondal Road, Rajkot-360004

Phone: +91 $7984477041 / 8733015996$

Email: ravikothari19@gmail.com

Date of Submission $\quad: 19 / 11 / 2020$

Date of Final Revision : 20/01/2021

Date of Acceptance : 26/01/2021

Financial or other Competing Interests: None.

Date of Publication $\quad: 28 / 02 / 2021$ 